International Journal of Current Advanced Research

ISSN: O: 2319-6475, ISSN: P: 2319 - 6505, Impact Factor: SJIF: 5.995

Available Online at www.journalijcar.org

Volume 6; Issue 5; May 2017; Page No. 3682-3685

DOI: http://dx.doi.org/10.24327/ijcar.2017.3685.0346

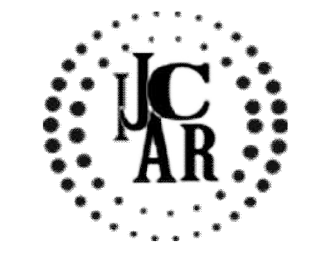

Research Article

\title{
A TRIP TO BRAIN FOR BETTER PERFORMANCE IN MATHEMATICS
}

\author{
Debjani Mandal18, Dr. Abhishek Basu1*8, Manali Biswas1, \\ Gunjan Dhar ${ }^{2}$ and Shamsuzzaman Ahmed ${ }^{3}$ \\ ${ }^{1}$ Department of Molecular Biology and Biotechnology, Sripat Singh College, Jiaganj, \\ Murshidabad, under University of Kalyani, West Bengal, India \\ 2 Department of Zoology, Sripat Singh College, Jiaganj, Murshidabad, \\ under University of Kalyani, West Bengal, India \\ 3 Principal and Department of Chemistry, Sripat Singh College, Jiaganj, Murshidabad, \\ under University of Kalyani, West Bengal, India
}

\section{A R T I C L E I N F O}

\section{Article History:}

Received $7^{\text {th }}$ February, 2017

Received in revised form $12^{\text {th }}$ March, 2017

Accepted $15^{\text {th }}$ April, 2017

Published online $28^{\text {th }}$ May, 2017

\section{Key words:}

Mathematics, Hippocampus, Prefrontal cortex, Parietal cortex, Anxiety, Neurogenesis, Exercise, Memory, Estrogen, Cathepsin

\begin{abstract}
A B S T R A C T
Brain, the most complex organ of the body with the largest neural network, associates its various parts in memory formation. Hippocampus and neocortex are important for answering problems with memorized mathematical facts. Hippocampus is more active in children compared to teenagers and adults. Children use fingers for counting, whereas adults depend on memory based information for solving a mathematical problem. Various parts of brain and the connections between these parts like posterior parietal cortex, ventrotemporal cortex, occipital cortex and prefrontal cortex are important for performance in mathematics. Neurogenesis in hippocampus plays a significant role in memory and learning. Exercise increases neurogenesis in hippocampus and in other parts of brain, which improves learning. Sex hormones affect brain development differentially in male and female. Sex hormones like estrogen promote neurogenesis by interacting with insulinlike growth factor-I and also promote development of connections between hippocampus and other parts of brain. Cathepsin B is a protein mainly involved in intracellular proteolysis. Exercise increases the expression of Cathepsin B. It crosses the blood-brain barrier and induces neurogenesis. The possible mechanism of its induction after exercise might involve estrogen receptor signaling pathway. cathepsin $B$ promoter has binding site for transcription factors like Specificity protein 1 (Sp 1), Erythroblast Transformation Specific family of transcription factors (ETS) and Upstream Stimulatory Factor (USF). Estrogen receptor might form complex with Sp1 followed by USF binding on cathepsin $B$ promoter. Therefore, increase in exercise can induce Cathepsin $B$ expression and promote neurogenesis which along with practice of mathematical problems can improve performance in mathematics.
\end{abstract}

Copyright $@ 2017$ Debjani Mandal et al. This is an open access article distributed under the Creative Commons Attribution License, which permits unrestricted use, distribution, and reproduction in any medium, provided the original work is properly cited.

\section{INTRODUCTION}

The most complex organ of our body is brain. It comprises of the largest neural network of the body. Various parts of the brain are associated with the formation of memory. For instance, hippocampus deals with long term memory and establishes a connection between memory and emotions. Neocortex is associated with learning languages, sensory perceptions, spatial reasoning and conscious thoughts. Contrary to the adults and the teenagers, hippocampus in children shows more activity. Children use fingers to count

\section{*Corresponding author: Abhishek Basu}

Department of Molecular Biology and Biotechnology, Sripat Singh College, Jiaganj, Murshidabad, under University of Kalyani, West Bengal, India sums, whereas teenagers and adults with more connections between hippocampus and neocortex, use memorized mathematical facts or memory based information to solve a problem [Geary DC et al., 2004; Quin S et al., 2014]. This is due to the fact that, as the child ages the activity of the hippocampus and the prefrontal-parietal engagement decreases, whereas connections between multiple cortical regions and hippocampus increase. This leads to a change in the strategy used for solving mathematical problems, from counting fingers to use of memorized mathematical facts (Figure 1). Brain characteristics strongly affect the ability of a person to solve mathematical problems. Proficiency in mathematics can be predicted from the development of posterior parietal cortex, ventrotemporal cortex, occipital cortex and prefrontal cortex. Individuals show variation in these regions in terms of volume; greater the gray matter 
better will be the performance in mathematics over time. Therefore, various regions of the brain, their respective volumes and the connections between these regions are significant determinant of performance in mathematics. Girls and boys can perform equally well in mathematics. There is no gender bias with respect to performance in mathematics [Devine A et al., 2012]. However, high levels of mathematics anxiety have been reported in girls. An inverse relationship has been suggested between mathematics anxiety and performance in mathematics [Carey E et al., 2015]. Therefore, mathematics anxiety might reduce the performance of girls in mathematics [Devine A et al., 2012].

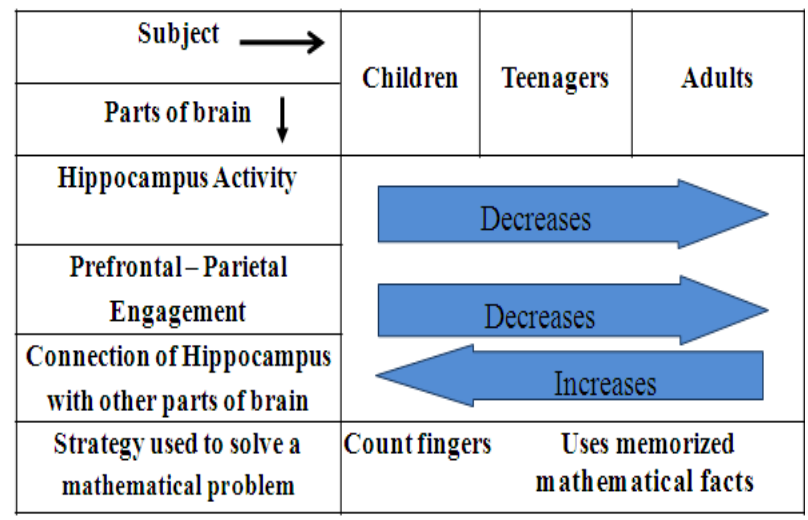

Figure 1. Activity, engagement and connection of various parts of the brain in different age groups, while solving a mathematical problem

\section{Exercise increases neurogenesis}

Neurogenesis in hippocampus influences hippocampus dependent learning and memory. Hippocampal neurogenesis is induced by long term aerobic training. Exercise also improves learning [Hwang DS et al., 2016]. Genetic constitution of an individual regulates extent of response of neurogenesis to physical exercise [Nokia MS et al., 2016]. Exercise promotes cell proliferation, neuron growth and expression of various neurotrophic signaling molecules like BDNF (Brain Derived Neurotrophic factor), GDNF (Glial cell line Derived Neurotrophic Factor), VEGF (Vascular Endothelial Growth Factor), IGF-I (Insulin-like Growth Factor-I) and C-Fos [van Praag H et al., 1999; Lee TM et al., 2014]. These signaling molecules promote blood vessels formation in the brain and neurogenesis in adults. Aerobic exercise also increases the volume of gray matter in various parts of brain like in prefrontal cortex, hippocampus, parietal cortex and cerebellum [Gomez-Pinilla $\mathrm{F}$ and Hillman C, 2013]. All these factors lead to improvement of cognitive behavior, spatial memory and working memory with the enhancement of academic performance in children (Figure 2).

\section{Role of estrogen in neurogenesis}

Neurogenesis in hippocampus is also affected by sex hormones, differentially in male and female [Barker JM and Galea LA, 2008]. Choroid plexus is the interface between blood and cerebrospinal fluid. It releases various signaling molecules which regulate behavior of neural stem cells [Johansson PA, 2014]. Estrogen and androgen influence the biological functions of choroid plexus, thereby playing a vital role in brain development [Santos CR et al., 2017]. Adult hippocampal neurogenesis can also be regulated by interaction between growth factors and hormones. For example, insulin-like growth factor-I and estradiol (the predominant estrogen during reproductive years in terms of estrogenic activity) has been found to promote neurogenesis in hippocampus [Garcia-Segura LM et al., 2010]. Such kind of interactions may also regulate various brain development and neuroplastic events. Estradiol can increase the proliferation and differentiation of new neurons, which promotes the connections of hippocampus with other parts of the brain in a sex specific manner [Kight KE and McCarthy MM, 2017]. Thus, sex hormones like estrogen can influence hippocampus dependent cognition, spatial and contextual memory by promoting neurogenesis.

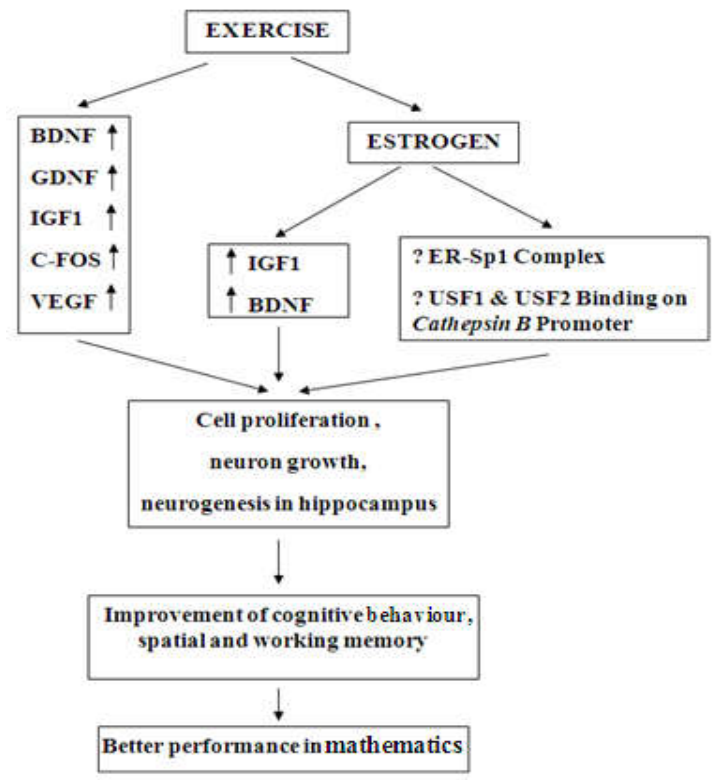

Figure 2 Role of exercise andestrogen in neurogenesis and subsequent performance in mathematics

\section{Cathepsin B and Neurogenesis under Estrogen Receptor Signaling}

Cathepsin B is a lysosomal cysteine protease mainly involved in intracellular proteolysis. It is encoded by $c t s b$ gene. It is over expressed in various cancers. Recently, Cathepsin B protein expression has been found to be upregulated in muscle and blood of mice, monkey and human after doing exercise [Moon HY et al., 2016]. Cathepsin B can cross blood-brain barrier and can increase the expression of molecules important for neurogenesis. Increased Cathepsin B level improves performance on complex recall tasks, such as drawing from memory. Though no previous study have reported that Cathepsin B expression is induced downstream to estrogen signaling, transcription of $c t s d$ gene (encodes a lysosomal aspartyl protease Cathepsin D) is induced by formation of estrogen receptor- Sp1 (transcription factor Specificity protein 1) complex followed by binding of USF (Upstream Stimulatory Factor) 1 and 2 on ctsd promoter in breast cancer cells [Xing W and Archer TK, 1998; Safe S, 2001; Wang F et al., 2001]. ctsb promoter possesses the binding sites for Sp1, ETS (Erythroblast Transformation Specific family of transcription factors) and USF (Figure 2) [Yan S et al., 2000]. Also, Cathepsin B expression increases with increase in expression of estrogen receptor in breast cancer cells [Sun T et al., 2016]. Therefore, from the above evidences it can be hypothesized that Cathepsin B over expression can be induced downstream of estrogen signaling pathway upon exercise, leading to neurogenesis in 
hippocampus and other parts of brain. This along with practice of mathematical problems can improve performance in mathematics.

\section{DISCUSSION}

Brain, the most complex organ of our body determines our performance in mathematics. Children have more active hippocampus compared to adults and teenagers. They use fingers to count sums, whereas adults depend on memory based mathematical facts for solving a mathematical problem. There is no gender bias with respect to performance in mathematics. However, girls are reported to show high level of mathematics anxiety, which can decrease their performance in mathematics. Various studies have highlighted the significance of neurogenesis in memory and learning. Neurogenesis in hippocampus and other parts of brain is induced by exercise. Aerobic training promotes cell proliferation, neuron growth and expression of various neurotrophic signaling molecules in brain. It also increases gray matter volume in various parts of the brain like in prefrontal cortex, hippocampus, parietal cortex and cerebellum. This improves cognitive behaviour, spatial memory and working memory leading to better academic performance in children. Sex hormones like estrogen influence hippocampus dependent cognition, spatial and contextual memory, by promoting neurogenesis. Estrogen and androgen influence the biological functions of choroid plexus. Estradiol interacts with IGF-I and promotes neurogenesis in hippocampus. Cathepsin B is a lysosomal cysteine protease involved in intracellular proteolysis. Cathepsin B can increase the expression of various molecules important for neurogenesis. Increase in Cathepsin B level improves the performance on complex recall tasks, such as drawing from memory. Cathepsin B is encoded by $c t s b$ gene, which has Sp1, ETS and USF binding elements on its promoter. Cathepsin B expression increases with increase in expression of estrogen receptor in breast cancer cells. It can be hypothesized that Cathepsin B expression can be induced downstream of estrogen receptor signaling pathway upon exercise, by formation of $\mathrm{Spl-estrogen}$ receptor complex followed by binding of USF 1 and 2 on the $c t s b$ gene promoter, as it happens in case of ctsd gene (gene encoding Cathepsin D protein). Further research is needed to understand the role of Cathepsin B in neurogenesis and how it leads to better performance in mathematics.

\section{Acknowledgement}

We are grateful to Prof. Indranil Saha, Dr. Debaprasad Panda, Dr. B. M. Uzzal Afsan and Prof. Sakti Mandal of Sripat Singh College for their guidance and support during the course of the research. We acknowledge Department of Biotechnology, Government of West Bengal for the financial assistance.

\section{References}

Barker JM, Galea LA. 2008. Repeated estradiol administration alters different aspects of neurogenesis and cell death in the hippocampus of female. But not male, rats. Neurosci., 152(4): 888-902.

Carey E, Hill F, Devine A, Szücs D. 2016. The Chicken or the Egg? The Direction of the Relationship Between Mathematics Anxiety and Mathematics Performance. Front. Psychol., 6: 1987.
Devine A, Fawcett K, Szücs D, Dowker A. 2012. Gender differences in mathematics anxiety and the relation to mathematics performance while controlling for test anxiety. Behav. Brain Funct., 8: 33.

Garcia-Segura LM, Arévalo MA, Azcoitia I. 2010. Interactions of estradiol and insulin-like growth factor-I signalling in the nervous system: new advances. Prog. Brain Res., 181: 251-72.

Geary DC, Hoard MK, Byrd-Craven J, De Soto MC. 2004. Strategy choices in simple and complex addition: Contributions of working memory and counting knowledge for children with mathematical disability. J. Exp. Child. Psycho., 88(2):121-51.

Gomez-Pinilla F, Hillman C. 2013. The Influence of Exercise on Cognitive Abilities. Compr. Physiol., 3(1): 403428.

Hwang DS, Kwak HB, KoI G, Kim SE, Jin JJ, Ji ES, Choi HH, Kwon OY. 2016 . Treadmill Exercise Improves Memory Function Depending on Circadian Rhythm Changes in Mice. Int. Neurourol. J., 20(Suppl 2): S141-149.

Johansson PA. 2014. The choroid plexuses and their impact on developmental neurogenesis. Front. Neurosci., 8: 340.

Kight KE, Mc Carthy MM. 2017. Sex differences and estrogen regulation of BDNF gene expression, but not pro peptide content, in the developing hippocampus. J. Neurosci. Res., 95(1-2): 345-354.

Lee TM, Wong ML, Lau BW, Lee JC, Yau SY, So KF. 2014. Aerobic exercise interacts with neurotrophic factors to predict cognitive functioning in adolescents. Psycho. Neuro. endocrinology., 39: 214-24.

Moon HY, Becke A, Berron D, Becker B, Sah N, Benoni G, Janke E, Lubejko ST, Greig NH, Mattison JA, Duzel E, van Praag H. 2016. Running-Induced Systemic Cathepsin B Secretion Is Associated with Memory Function. Cell Metab., 24(2): 332-40.

Nokia MS, Lensu S, Ahtiainen JP, Johansson PP, Koch LG, Britton SL, Kainulainen H. 2016. Physical exercise increases adult hippocampal neurogenesis in male rats provided it is aerobic and sustained. J. Physiol., 594(7): 1855-73.

Qin S, Cho S, Chen T, Rosenberg-Lee M, Geary DC, Menon V. 2014. Hippocampal-neocortical functional reorganization underlies childrens' cognitive development. Nature Neurosci., 17: 1263-1269.

Safe S. 2001. Transcriptional activation of genes by 17 betaestradiol through estrogen receptor-Sp1 interactions. Vitam Horm., 62: 231-52.

Santos CR, Duarte AC, Quintela T, Tomás J, Albuquerque T, Marques F, Palha JA, Gonçalves I. 2017. The choroid plexus as a sex hormone target: Functional implications. Front. Neuroendocrinol., 44: 103-121.

Sun T, Jiang D, Zhang L, Su Q, Mao W, Jiang C. 2016. Expression profile of cathepsins indicates the potential of cathepsins B and D as prognostic factors in breast cancer patients. Oncol. Lett., 11(1): 575-583.

van Praag H, Kempermann G, Gage FH. 1999. Running increases cell proliferation and neurogenesis in the adult mouse dentate gyrus. Nat. Neurosci., 2(3):26670 . 
Wang F, Samudio I, Safe S. 2001. Transcriptional activation of cathepsin D gene expression by 17 beta-estradiol: mechanism of aryl hydrocarbon receptor-mediated inhibition. Mol. Cell Endocrinol., 172(1-2): 91-103.

Xing W, Archer TK. 1998. Upstream stimulatory factors mediate estrogen receptor activation of the cathepsin D promoter. Mol. Endocrinol., 12(9): 1310-21.
Yan S, Berquin IM, Troen BR, Sloane BF. 2000. Transcription of human cathepsin $\mathrm{B}$ is mediated by Sp1 and Ets family factors in glioma. DNA Cell Biol., 19(2): 79-91.

\section{How to cite this article:}

Debjani Mandal et al (2017) ' A review on singular perturbed delay differential equations', International Journal of Current Advanced Research, 06(05), pp. 3682-3685.

DOI: http://dx.doi.org/10.24327/ijcar.2017.3685.0346 